\title{
Imaging the pathophysiology of major depressive disorder - from localist models to circuit-based analysis
}

Michael T Treadway ${ }^{*}$ and Diego A Pizzagalli*

\begin{abstract}
The neuroimaging literature of Major Depressive Disorder (MDD) has grown substantially over the last several decades, facilitating great advances in the identification of specific brain regions, neurotransmitter systems and networks associated with depressive illness. Despite this progress, fundamental questions remain about the pathophysiology and etiology of MDD. More importantly, this body of work has yet to directly influence clinical practice. It has long been a goal for the fields of clinical psychology and psychiatry to have a means of making objective diagnoses of mental disorders. Frustratingly little movement has been achieved on this front, however, and the 'gold-standard' of diagnostic validity and reliability remains expert consensus. In light of this challenge, the focus of the current review is to provide a critical summary of key findings from different neuroimaging approaches in MDD research, including structural, functional and neurochemical imaging studies. Following this summary, we discuss some of the current conceptual obstacles to better understanding the pathophysiology of depression, and conclude with recommendations for future neuroimaging research.
\end{abstract}

Keywords: Major Depression, Neuroimaging, PET, MRI, Serotonin, Dopamine, MRS, Glutamate, GABA, Inflammation

\section{Introduction}

The neuroimaging literature of Major Depressive Disorder (MDD) has exploded in recent years, with the current pace of research including over 250 new articles listed each year in PubMed alone. A substantial majority of these studies have been focused on identifying putative biological and neural variables that differentiate individuals with MDD from psychiatrically healthy controls. This program of research has been successful in demonstrating a large number of abnormalities in MDD samples, including alterations across measures of brain structure and function; endocrine, immune and neurotransmitter systems; and large-scale network organization. Despite this progress, however, fundamental questions remain about the pathophysiology and etiology of MDD as well as the strengths and pitfalls of neuroimaging methodologies in attempting to answer them.

\footnotetext{
* Correspondence: mtreadway@mclean.harvard.edu; dap@mclean.harvard. edu

Center for Depression Anxiety and Stress Research, McLean Hospital/Harvard Medical School, 115 Mill Street, Belmont, MA 02478, USA
}

Even more importantly, this body of work has yet to influence clinical practice in any substantive way. A longstanding goal of clinical psychology and biological psychiatry research has been the development of objective tests for diagnosing mental disorders. Frustratingly little progress has been made on this front, however, and the 'gold-standard' of diagnostic validity and reliability remains expert consensus, a practice that is essentially unchanged from Meehl's day [1]. Despite our capacity to measure an astonishing array of biological signals in MDD patients, we have yet to find a single measure - or a combination of variables - that tracks symptom expression with the requisite specificity and sensitivity to be reliably meaningful in the clinic.

It is against this backdrop that we present the current review. First, we provide a (non-exhaustive) summary of the major findings that have emerged from different neuroimaging approaches. This includes a review of structural, functional, neurochemical, neuroendocrine and neuroimmune imaging studies in MDD. Following this summary, we discuss some of the current conceptual obstacles to better understanding the pathophysiology of 
depression, and present the use of circuit-based analysis as a methodological path forward.

\section{Review}

\section{Neuroimaging and the pathophysiology of MDD} Morphometric neuroimaging studies

A large number of studies in MDD patients to date have identified structural alterations across multiple tissue classes. These findings have been summarized using me ta-analytic approaches reporting on structural alterations observed using regions-of-interest (ROI) tracingbased methods [2,3], voxel-based methods (VBM) [4], post-mortem tissue analysis [5], and diffusion tensor imaging of white-matter integrity [6]. Tracer-based methods have provided especially strong evidence for reduced hippocampal volume and enlarged ventricles in MDD [3]. These results have been recapitulated by voxel-based methods, which additionally implicate a more distributed network of structural alterations associated with MDD, including the anterior cingulate cortex (ACC), medial prefrontal cortex (mPFC), orbitofrontal cortex (OFC), dorsolateral prefrontal cortex (dlPFC), the striatum, and the amygdala. A limitation of these findings is that they are mostly drawn from cross-sectional designs. Therefore, it is difficult to know whether such structural differences represent a biological diathesis, a compensatory adaptation, or a consequence of the illness.

A handful of longitudinal studies have addressed this significant limitation by investigating structural changes as a function of depressive state and treatment outcome. IFor some regions, including the hippocampus and medial prefrontal areas, several studies have suggested that greymatter volume may decline monotonically over multiple depressive episodes $[7,8]$. In contrast, the amygdala may become enlarged prior to a first depressive episode [9]. Structural integrity of these regions has also been found to partially predict symptom remission. Specifically, hippocampal volumes have been found to prospectively correlate with treatment outcome at both one- and three-year follow-ups [10,11], and longitudinal studies have found that decreased hippocampal volumes were partially restored following successful treatment or spontaneous remission [11-13]. Importantly, similar morphometric changes in these regions have also been associated with high levels of trait negative affect in non-depressed individuals who have an elevated polygenic risk profile for developing MDD. This has been observed using both genome-wide analysis [14] and examinations of non-depressed individuals with a family history of MDD [15,16], consistent with the hypothesis that these structural decreases likely reflect an endophenotype marker [17].

Taken together, structural imaging studies have found robust evidence for group-level differences in grey-matter volume across cortical and sub-cortical areas. Longitudinal studies provide the strongest evidence linking these changes to the onset and remission of a depressive state, suggesting that they are either causally involved in MDD or that they at least meaningfully fluctuate with illness progression. Future longitudinal work, especially with prospective-cohort designs, will help further elucidate the role of these morphometric alterations in the etiopathophysiology of MDD.

\section{Functional neuroimaging studies}

Functional imaging studies of MDD have also grown substantially over the last two decades, with a wide variety of functional domains probed using a large number of tasks. We will therefore limit our focus to two general domains that have been most frequently examined in depression studies: (1) emotion processing and regulation, and (2) reward processing (Figure 1). For a more comprehensive discussion of other aspects of the functional neuroimaging literature in major depression, we refer readers to several excellent recent reviews and metaanalyses: [18-20].

Functional neuroimaging of emotion processing Arguably the most common domain assessed by functional imaging studies of depression is responses to emotional stimuli. Examples include studies of responses to both explicit and implicit presentations of affect-laden stimuli [21-23], recruitment of cognitive control mechanisms required to gate out affective 'distractors' during simple working memory and attention tasks [24,25], and deliberate top-down control of affective responses to positive and negative stimuli [26-29]. The most replicated result observed during passive presentation of emotional stimuli is a heightened responsivity in limbic regions - especially the amygdala - to negatively valenced stimuli in depressed individuals. For tasks that require subjects to efficiently 'gate-out' affective content in order to better attend to non-emotional aspects of a task or stimulus, elevated limbic activity is often accompanied by hypo-activation in prefrontal areas, including aspects of ventromedial PFC, ventrolateral prefrontal cortex (vlPFC), ACC, and dlPFC. It is noteworthy that these same regions frequently exhibit volumetric abnormalities.

While prefrontal hypo-activations are commonly interpreted as evidence of a top-down control 'deficit', it is unclear whether they reflect a local deficit in network recruitment or simply a failure to engage in the task as effectively as controls. Interestingly, when task performance is matched across depressed and non-depressed individuals, there is evidence for hyper-response in prefrontal areas [30,31], possibly indicating cortical inefficiency. In addition, the specificity of alterations in amygdalar and prefrontal networks to depression is unclear, as similar patterns are frequently observed in studies of anxiety, and 


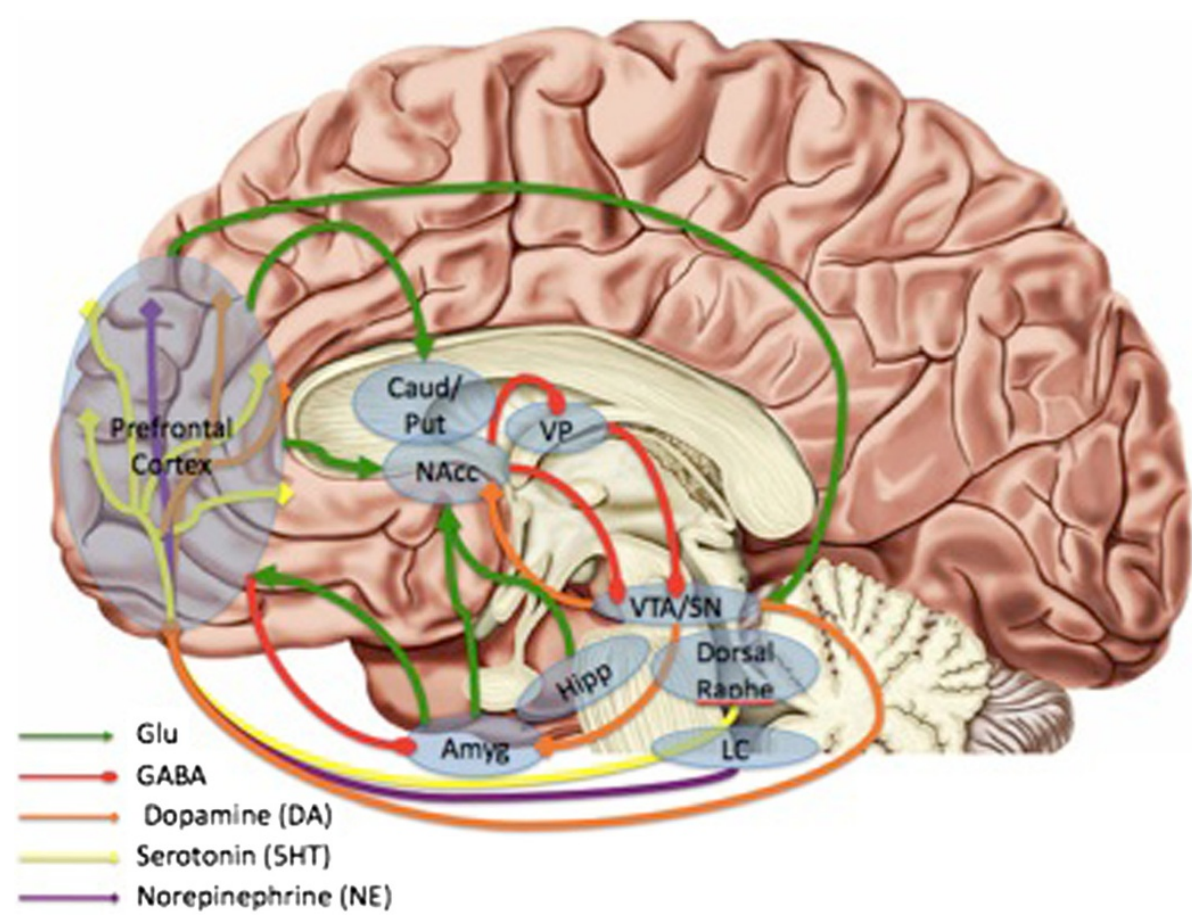

Figure 1 Regions, transmitters and circuits implicated in the pathology of major depressive disorder (MDD) by human neuroimaging studies. Past studies have identified alterations in monoamine levels and receptor availability as well as alterations in glutamate and GABA. These neurotransmitter systems participate in larger circuits involved in the experience and regulation of emotion, responses to stress, and processing of rewards. Note: placement of structure labels is approximate. Amyg = amygdala; Caud = Caudate; GABA = GABAergic projections; Glu=glutamatergic projections; Hipp = hippocampus; NAcc = nucleus accumbens; Put = Putamen; SN = substantia nigra; VP = ventral pallidum; VTA = ventral tegmental area. Republished with permission from Treadway and Zald [49].

only a few direct comparison studies have been conducted to date $[32,33]$. Future research is needed to further isolate the specific alterations in cortico-limbic responses to emotion in MDD, and to determine the extent to which these effects are specific to a depressed mood or rather represent a common mechanism associated with other forms of internalizing psychopathology.

In contrast to experimental paradigms that require either passive emotional processing or implicit emotion regulation in the form of attentional control, findings of studies of directed emotion regulation in MDD are highly variable. In healthy controls, down-regulation of negative emotion has been consistently associated with increased activation in medial and dIPFC areas and reduced activity in the amygdala [34]. These observations, combined with observations of impaired functional coupling between mPFC and amygdala during passive viewing of affective stimuli [35], led investigators to hypothesize that depressed patients would be less successful in reducing amygdala reactivity - and associated negative emotions - when explicitly regulating emotional responses to negative stimuli. Empirical support for this hypothesis, however, has been mixed. Only one study has reported that depressed patients experience more difficulty in decreasing sadness than controls [26], while others have found no differences [27-29]. These studies have also generally failed to observe impaired cortico-amygdala interactions during explicit emotion regulation in MDD. Consequently, these data suggest that emotion regulation deficits in MDD do not reflect a true inability to regulate emotion when explicitly directed to do so, at least not in the context of typical laboratory-based affective stimuli.

Functional neuroimaging of reward processing Another primary area of functional neuroimaging research in MDD involves responses to rewarding stimuli. While early functional magnetic resonance imaging (fMRI) (and non-imaging) studies frequently operationalized reward in terms of the passive viewing or consumption of positively valenced stimuli (for example [36-38]), more recent work has increasingly emphasized constructs of reward anticipation [39-42], reinforcement learning $[43,44]$ and motivation [45-47], which are psychologically and neurobiologically distinct. This shift has been motivated largely by the enhanced understanding of functional segregation of dopaminergic cortico-striatal systems in reward processing, which have been found to underlie anticipation, learning, and salience of rewards, rather than affective responses to them [48]. Indeed, 
reward-related symptoms are especially amenable to a translational neuroscience approach, given how well characterized reward-related pathways are by both preclinical and human neuroeconomic studies (see [49] for a longer discussion). The most common observation from this body of work is hypo-recruitment in MDD patients of striatal regions associated with reward salience, anticipation and learning, possibly reflecting alterations in the availability of pre-synaptic pools in dopaminergic afferents to striatal sub-regions [50-52] (see also discussion of dopamine imaging studies below). In addition, altered crosstalk between cortical and ventral striatal regions has been associated with rapid habituation to rewarding stimuli, which is also consistent with anhedonic presentation [53].

In sum, these studies highlight cortico-striatal pathways as critically involved in specific symptom domains of MDD. Of note, there is arguably greater consistency in studies of reward processing in MDD than of other cognitive processes. This may reflect the fact that reward processing studies have focused on a more homogeneous symptom domain and that the neurobiology of normative reward functioning is better understood.

\section{Neurochemical imaging studies in MDD}

The hypothesis that specific neurotransmitter systems represent a core pathology of mood disorders is among the oldest in biological psychiatry (see, for example, Schildkraut [54]). For most of modern psychiatric history, this line of work has emphasized alterations in monoamines, given early observations that administration of various monoamine-reducing drugs or pharmacological manipulations could induce depressive symptoms. It was only decades later, however, when the in vivo visualization of these signaling pathways could be achieved.

Currently, the two most widely used approaches to neurochemical imaging in psychiatric populations are Positron Emission Tomography (PET) and Magnetic Resonance Spectroscopy (MRS). A less commonly used technique is Single Photon Emission Computed Tomography (SPECT). Both PET and SPECT rely on the measurement of radioactive decay from an injected isotope as the basis of targeting the spatial distribution of a particular receptor or protein. In contrast, MRS takes advantage of the different magnetic resonance signatures associated with distinct molecular compounds, and can be useful for quantifying the availability of relatively abundant neurotransmitters such as glutamate (Glu) and $\gamma$-aminobutyric acid (GABA). Both of these methods have contributed to the study of pathophysiology in MDD, and are notable for both their positive and null findings. In this section, we review some of the primary neurotransmitter systems that have been investigated in MDD using these techniques.
Neurochemical imaging of serotonin systems in MDD Interest in serotonin (5-HT) has been central to depression research over the last three decades, owing primarily to reported success of antidepressant pharmacotherapies that selectively target the serotonergic system in both humans and animal models. Evidence from preclinical studies further supports a role for serotonin in MDD symptoms, particularly those related to the processing of stress. Under normal conditions of wakefulness, serotonin neurons are tonically active [55] and the distribution of serotonergic tone is relatively even across most brain regions [56] - a pattern that has been found to support normal network functioning for a variety of cognitive and goaldirected behaviors. In contrast, exposure to stress can produce a surge in 5-HT signaling, which has been found to disrupt the emotion-regulatory functions of corticoamygdalar networks [57]. Further, evidence suggests that medial prefrontal projections to serotonin-releasing neurons in the dorsal raphe play a crucial role in determining adaptive versus non-adaptive responses to stress [58,59]. Consequently, impaired serotonin signaling may be a substrate involved in stress vulnerability and a key risk factor in the development of MDD [60-62].

For these reasons, serotonin is among the most widely imaged neurochemical systems in MDD, with over 35 studies exploring group differences in the expression of serotonin receptor sub-types as well as the serotonin transporter (for recent reviews, see [63,64]). To date, however, results have been mixed, with investigators frequently reporting higher or lower serotonin receptor or transporter expression in MDD participants than in controls [63]. For example, of the 15 studies investigating expression of $5-\mathrm{HT}_{1 \mathrm{~A}}$ receptor in depressed patients relative to healthy controls, nine reported decreased expression in MDD, four reported increased expression, and two observed no change. Similar discrepancies have been observed for other proteins involved in 5-HT signaling pathways, including the $5-\mathrm{HT}_{2 \mathrm{~A}}$ receptor, $5-\mathrm{HT}_{1 \mathrm{~B}}$ receptor, and the serotonin transporter (SERT).

It is important to note that most of these studies are relatively small in size (between 9 and 22 MDD patients) and are, therefore, underpowered to explore withinsample relations between serotonin function and specific symptom dimensions. This is a potentially critical limitation, as the substantial heterogeneity of MDD is likely to be associated with divergent effects on neurotransmitter systems. In addition, most of these studies have not investigated the function of serotonin signaling systems, compared to baseline expression. Moreover, no longitudinal studies have been performed. Therefore, as with cross-sectional studies of structure or function, it is difficult to know whether 5HT abnormalities should be interpreted as a primary deficit, a downstream consequence, a risk factor, or a compensatory mechanism. 
What is clear, however, is that to the extent that the 5-HT system is involved in the etiopathophysiology, its effect size is modest, and likely dependent on interactions with numerous other systems.

\section{Neurochemical imaging of catecholamine systems in} MDD Other monoamines that have long been associated with MDD are the catecholamines dopamine (DA) and norepinephrine (NE) $[65,66]$. DA is well established as being necessary for motivation, reward-based learning, and goal-directed behavior $[48,67,68]$ and, therefore, is believed to be a substrate of reward-related symptoms such as anhedonia, fatigue, and anergia in psychiatric disorders $[69,70]$. Unlike 5-HT, which is relatively uniform in its distribution across the brain, DA expression is densest in the striatum, a key structure involved in valuation, decision-making and action.

Neuroimaging evidence for altered DA systems in MDD comes primarily from PET, SPECT and pharmacological challenge studies. This research has found that MDD is associated with changes in DA synthesis capacity as indexed by L-3,4-dihydroxyphenylalanine (L-DOPA) uptake [71], as well as changes in the regional distribution and availability of DA receptors, and the DA transporter (DAT). As with the 5-HT studies summarized above, however, imaging studies of DA systems have produced conflicting results. In PET and SPECT studies of DAT, MDD has been associated with both lower [72] and higher [73-75] binding potential in the striatum. Interestingly, all studies reporting DAT increases have used SPECT, which has much lower sensitivity than PET [76] and often employed tracers that have equal affinity for the SERT and DAT (for example, $\beta$-CIT) and thus do not allow conclusive interpretations. Moreover, post-mortem studies support the observation of reduced DAT expression [77].

Studies of DA receptor availability in MDD have also yielded mixed results. In some cases, increased striatal D2/D3 receptor binding has been shown to occur in heterogeneous depressed samples [78,79]. This increase in D2/D3 receptor availability appears to contradict animal data in which antidepressant responses are associated with increased D2-like binding in the striatum [80]. Other studies using medication-naïve or medication-free patients have failed to find group differences in striatal receptor binding [81,82], while one additional small study reported variable changes in D2-like binding following treatment with selective serotonin reuptake inhibitors (SSRIs) with patients who showed increased binding exhibiting more clinical improvement than those who did not [83]. With respect to the D1 receptor, fewer studies have examined this system given the lack of available ligands that reliably distinguish between the $\mathrm{D} 1$ and serotonin $5-\mathrm{HT}_{2 \mathrm{~A}}$ receptor, especially in extrastriatal areas where the receptor density of $\mathrm{D} 1$ and $5 \mathrm{HT}_{2 \mathrm{~A}}$ is roughly equivalent. One study reported reduced D1 availability in left middle caudate [84], but this finding has not yet been replicated. Taken together, these studies suggest a possible role of D2-like receptors in downstream effects of antidepressant treatment, although the precise nature of the effect and how alterations in D2-like receptor availability may be related to DA function are unclear.

As with other conflicting reports in neuroimaging studies of MDD, part of the discrepancy across studies likely reflects the heterogeneity of the disorder. Supporting this assertion is the observation of slightly more consistent effects when MDD samples are selected on the basis of a particular symptom profile. For example, one study that restricted its MDD patient sample to individuals with anhedonic symptoms reported decreased DAT binding [85]. In addition, L-DOPA alterations in the striatum are present in depressed individuals with flat affect or psychomotor slowing, but not in depressed individuals without these symptoms $[86,87]$. Decreases in DA synthesis have also been observed in patients who develop depressive symptoms after undergoing IFN- $\alpha$ therapy [50]. This therapy stimulates inflammation signaling cascades, which have been found to disrupt DA synthesis, and may provide a link between elevated inflammation in MDD and specific symptoms related to perturbances of DA signaling, such as motivation and anhedonia $[50,88]$. Overall, these studies provide mixed evidence for general DA alterations in MDD, with additional evidence highlighting the importance of examining links between DA systems and specific symptoms in MDD, rather than in the disorder as a whole.

In contrast to DA, molecular imaging methods of $\mathrm{NE}$ signaling pathways have been much slower to develop. Currently, only studies of the NE transporter (NET) have been performed in MDD [89], with no studies examining NE receptors in MDD due to a lack of available ligands. Pharmacological functional imaging studies have also been used to indirectly explore effects of NE-increasing agents, though many of these studies have used drugs such as duloxetine, which simultaneously target both 5-HT and NE transporters. Duloxetine reduced connectivity within resting-state and task-positive networks, [90], and boosted ventral striatal responses during a reward task [91], while the NET-selective agent reboxetine increased thalamic dorsolateral prefrontal responsivity to emotional pictures $[92,93]$. While these studies provide promising leads, insufficient functional or molecular imaging work of NE function in the context of MDD is available, despite significant evidence for its role in the disorder [94].

Neurochemical imaging of glutamatergic and GABAergic systems in MDD In recent years there has been substantial interest in the contribution of non-monoamine neurotransmitters to the pathophysiology of MDD, 
particularly the excitatory and inhibitory amino acid transmitters of glutamate (Glu) and GABA, respectively. At an intuitive level, the hypothesis that these systems would be implicated in depression holds significant appeal; the innervation of Glu- and GABA-releasing neurons vastly outnumbers all other neurotransmitter systems in the brain, making these two neurochemicals responsible for the bulk of information processing related to learning, cognition, memory, and decision-making [95]. When considering the scope of this diverse functional anatomy, it is difficult to imagine that Glu and GABA would not be directly, or at least indirectly, involved.

Evidence for alterations of Glu transmission in MDD have long been reported, but findings have been mixed, with increased Glu levels observed in plasma samples and post-mortem tissue as compared to decreased levels found in neuroimaging studies [96-98]. These discrepancies may be due in part to the multiple roles that Glu plays in the brain (for a more extended discussion, see [99]). A recent meta-analysis or MRS imaging studies found that MDD was associated with a substantial decrease in Glu levels within the mPFC/ACC [100], though it should be noted that not all studies were able to distinguish between Glu and glutamine, a common metabolite of astrocyte reuptake processes. Studies published after this meta-analysis provided additional evidence of reduced Glu concentration in the MPFC of MDD subjects [101-103], and similar alterations have also been detected in children with depressive symptoms [104] as well as remitted MDD subjects [102], raising the possibility that they constitute a trait-like vulnerability factor for MDD. Highlighting the clinical significance of these findings, among MDD subjects, increased pre-treatment Glu levels predicted better electroconvulsive therapy (ECT) response [103].

PET imaging studies of metabotropic Glu receptors have also revealed changes in Glu signaling pathways in MDD [105] and in relation to MDD symptoms [106]. The rapid antidepressant effects of ketamine, an N-methyl-Daspartate (NMDA) partial agonist $[107,108]$ further implicate the Glu pathway. Finally, aberrations in Glu signaling and Glu neurotoxicity have been associated with mPFC volumetric reductions discussed above [95]. In sum, while investigation of Glu dysfunction in MDD is relatively new, given the near ubiquitous distribution of Glu signaling throughout the brain, it is likely that many of the alterations in neural circuit function observed using fMRI studies partially reflect Glu-related pathology.

In contrast to Glu, studies of GABA are less frequent in MDD. GABA alterations have been documented in MDD $[17,109]$, including reports of reduced GABA levels in plasma and cerebrospinal fluid [110-112], as well as specific GABA reductions in the $\mathrm{MPFC}$ as assessed with MRS $[113,114]$. Moreover, GABA function in this region has been suggested to play a critical role in mediating negative feedback of hypothalamic-pituitary-adrenal (HPA)-axis activity $[115,116]$. Thus, decreased GABAergic tone may foment excess glucocorticoid exposure in mPFC, as reviewed above. The combination of increased glucocorticoid exposure and elevated GABA has been hypothesized to be a combination that may lead to increased excitotoxicity in these regions, thereby partially explaining the structural alterations in these areas summarized in the preceding section. To date, however, the number of studies focused on GABA is relatively small, making it difficult to draw firm conclusions.

Imaging neuroendocrine and neuroimmune systems in MDD Lastly, there has been growing interest in using neuroimaging to study the functional and structural consequence of other neurochemicals, such as hormones, factors and other endogenous signaling molecules. While technical limitations generally prevent the imaging of such molecules directly, their effects on structure and metabolism can nevertheless be observed using MRI. In the case of MDD, this work has focused most heavily on pro-inflammatory factors, including families of cytokines such as interleukins and interferons, hormones such as glucocorticoids (cortisol), thyroid stimulating hormone (TSH), and ghrelin $[117,118]$.

Dysregulation of stress hormones has been widely reported in MDD (albeit with significant variance), and is believed to partially mediate some of the observed structural alterations associated with the disorder, especially within the hippocampus and mPFC $[119,120]$. These regions are well known for playing a critical role in the regulation of stress hormones via direct and indirect projections to the hypothalamus, and have been shown to be structurally vulnerable to glucocorticoid-mediated excitotoxicity. Animal studies using either chronic stress protocols or local corticosteroid injections have repeatedly demonstrated tissue damage following excessive glucocorticoid exposure, including loss of dendritic spines and de-arborization [121-124]. In human studies, comparable relationships have been observed between daily cortisol levels and grey-matter volume in depressed patients [125]. Given that elevated stress is a major precipitant of first-time depressive episodes [60], the association between stress and regional microdamage is highly relevant.

In addition to stress hormones, depressive states have been strongly associated with an elevated inflammatory load [126,127], and there has been growing interest in signaling pathways related to the metabolic syndrome and excess adipose tissue as potential mediators of chronic low-grade inflammation [128,129]. Neuroimaging has therefore been employed as an aid to understanding the possible consequences of altered inflammatory and 
metabolic factors on neural systems [130,131]. Animal models suggest that elevations of peripheral cytokines and subsequent CNS microglia activation can disrupt the synthesis of both 5-HT and DA [132,133], and induce symptoms of fatigue and motivational anhedonia $[134,135]$. While direct evidence of increased microglia activity in MDD has not been detected using available PET ligands [136], functional neuroimaging studies have sought to better understand the downstream consequences of increased cytokine activity by examining correlations between peripheral cytokine levels and resting or task-induced fluctuations in Blood-OxygenLevel Dependent (BOLD) signals. Of note, healthy controls receiving an endotoxin challenge exhibited blunted neural responses to reward anticipation in the ventral striatum during a Monetary Incentive Delay (MID) task [137], similar to what is observed in MDD [42]. Further evidence comes from imaging studies of patients receiving IFN- $\alpha$ therapy. Following IFN- $\alpha$ treatment - which robustly increases inflammation - subjects exhibited decreased DA turnover within the striatum, as measured using a pre/post PET imaging of DA uptake with $\left[{ }^{18} \mathrm{~F}\right]$ Dopa (F-DOPA) [50]. By beginning to localize the functional architecture of brain regions that are affected by stress hormones and inflammation and by linking such abnormalities to specific cardinal symptoms of MDD (for example, anhedonia), these studies are playing a critical role in advancing a more precise understanding of depression symptomatology.

Summary of neuroimaging studies In review of the findings above, several themes emerge. The most promising result is that regardless of imaging modality, neuroimaging studies repeatedly isolate a similar network of regions in which MDD patients differ from controls. Indeed, the greatest success of neuroimaging studies in MDD has been to identify core nodes involved in the expression of depressive symptoms. Neural responses in cortico-striato-limbic circuits have been shown to discriminate between responders to different treatment modalities $[20,138]$ and have been the empirical foundation for new treatment techniques, such as deep brain stimulation (DBS) $[139,140]$ and transcranial magnetic stimulation (TMS) [141].

But this is perhaps where the good news ends; for while the same regions are often implicated, the direction of the effects is often contradictory (for example, greater or lesser BOLD signal, depending on the task). Moreover, some of this consistency is undoubtedly due to confirmatory bias in ROI selection; that is, reports of group differences in a given region increase the probability that future studies will focus on the region, either with targeted measurement (for example, volumetric tracing) or with more liberal statistical thresholds in voxel- based studies (for example, small-volume correction). Even when group differences emerge, they are often present only at the level of group average, with comparable ranges for both groups (for example, [142]). As a result, the field has been unable to identify any neural signature that may serve as useful biomarker in the diagnosis of MDD, and guide treatment selection.

The lack of stable pathophysiological markers of MDD after so many neuroimaging studies raises the possibility that the biological origins of depressive symptoms are simply too dynamic to produce consistent patterns using case-control designs. For example, many receptor subtypes, including those of monoamine, Glu and GABA pathways show rapid, activity-dependent changes in expression and ligand affinity [143]. This plasticity may be affected by the time of day, the amount of sleep someone received two nights before, and how much they have been taxing their working memory in recent weeks just as much as it is affected by MDD ([105,143]). Against all these additional sources of variance, it is perhaps unsurprising that cross-sectional designs have been unable to identify reliable biomarkers.

As a result, an increasing number of researchers have called for a better understanding of specific circuits that may mediate transdiagnostic symptom expression $[144,145]$. While much of this discussion has rightly emphasized the importance of animal models [146,147], the final section presents several conceptual and methodological approaches to clinical imaging studies that we feel may aid in the identification of circuits rather than regions.

\section{Future directions and circuit-based analysis}

A clear limitation of current neuroimaging studies in MDD has been the tendency to assess particular measures of brain function independently, despite clear evidence that these measures are highly inter-related. In contrast to measures of specific brain regions, chemicals, or tissue classes, circuit-based analysis provides a conceptual framework that is organized around a specific behavioral process. Circuits are defined by the combined structural and functional properties that enable a specific set of computations to be performed on a discrete set of inputs. As such, circuit-analysis integrates across many different levels and measures of brain function, but eschew the complexity of simultaneous whole-brain analysis. By focusing on discrete computations with a circumscribed array of possible inputs and outputs, circuit analysis meets the basic scientific requirement of simplification, but does so without neglecting biological complexity.

One of the most powerful and readily available methods for circuit-analysis in patient populations is functional connectivity. Whereas much of the first two decades of 
neuroimaging research emphasized localization of function to a particular brain region while individuals were either at rest or performing a particular task, growing appreciation for the role of functional networks has emerged in recent years. This shift reflects a broader recognition in the field of neuroimaging that the brain is comprised of discrete networks, which show local properties (for example, 'small-worldness') and can rapidly re-configure themselves to adapt to current environmental demands $[148,149]$. Consequently, focusing on task-driven changes within a single brain area provides only limited insight into the specific computations being performed. Indeed, significant progress has been made in the characterization of several stable networks that support domain-general functions, including attentional control, novelty and threat detection, default-mode and social cognition, and reinforcement learning and decision-making, all of which have been implicated in MDD [150] (Figure 2).

Complementing functional connectivity as a path towards understanding MDD from a systems-level approach is the growing use of multi-modal imaging. The most common example is the combined use of structural and function neuroimaging data. Such data are often collected together, as standard preprocessing pipelines for functional neuroimaging data typically require high-resolution structural scans [151]. More recently, the scope of multi-modal imaging studies has been expanded to include neurotransmitters such as monoamines, Glu and GABA. In an important study by Northoff and colleagues, researchers identified shifts in neurotransmitter availability of Glu and GABA as major drivers of altered functional responses to emotional stimuli in MDD [152]. Similarly, decreases in pre-synaptic striatal DA as measured using F-DOPA were associated with blunted ventral striatal BOLD signal during reward anticipation in depressed subjects, demonstrating a clear link between DA bioavailability and striatal responses to reward [50].

Another essential benefit of circuit-based analysis is the bridge it creates to behavioral and molecular neuroscience. Animal models play a pivotal role in testing causal hypotheses about brain function [146]. Such models are not only useful in aiding the interpretation of correlative neuroimaging data, they can also help refine the mapping of psychiatric symptom definitions to discrete and dissociable circuits. For example, the symptom of anhedonia - which was once perceived as a unitary construct tapping into the experience of pleasure - has gradually come to be recognized as involving multiple sub-components, including motivation and hedonic response, each of which involves distinct neural substrates $[69,70,153]$. However, because these sub-components in humans are often heavily correlated with each other at the level of symptom expression,

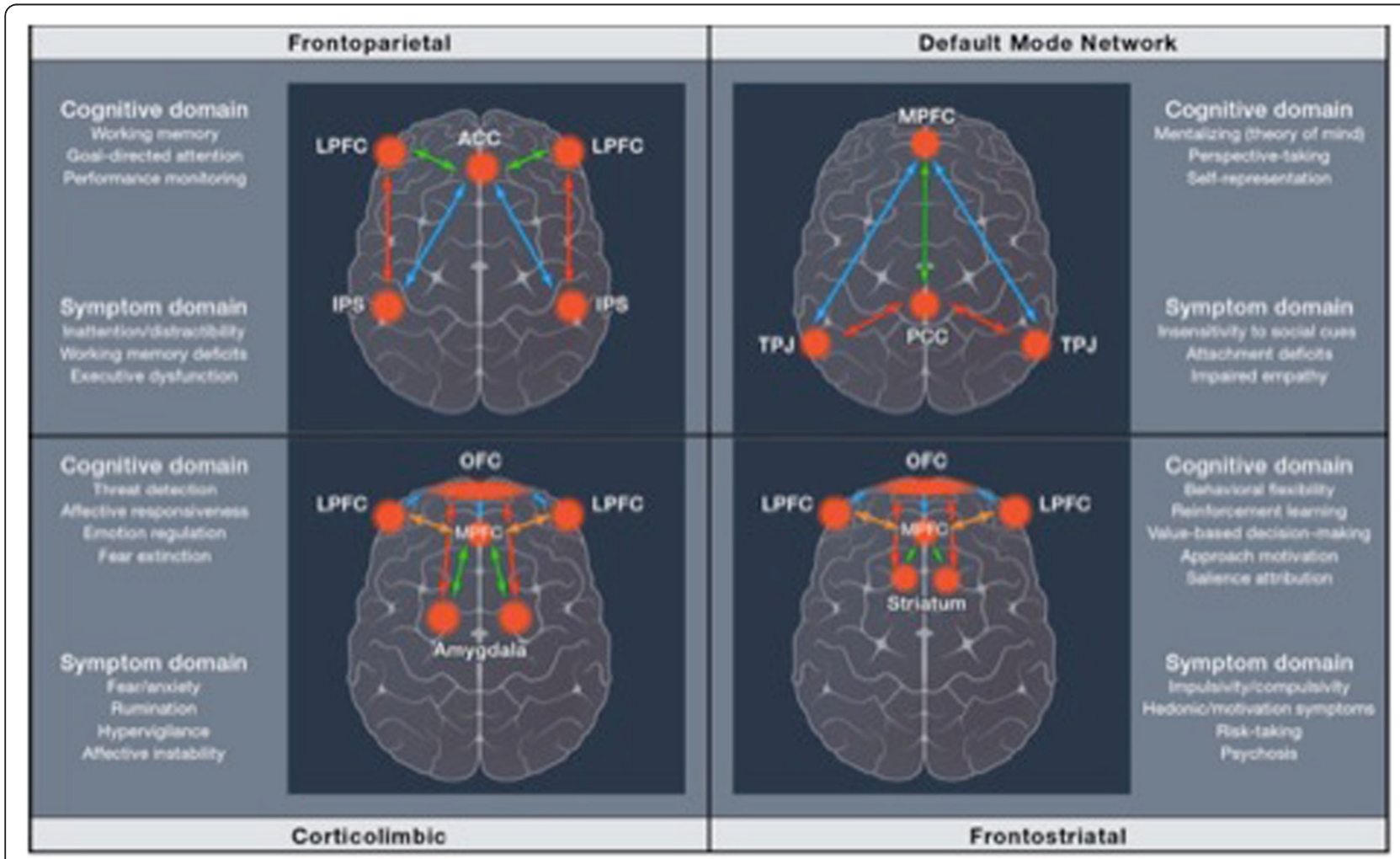

Figure 2 Schematic depiction of commonly identified functional networks and their associated cognitive and symptom domains. Republished with permission from Buckholtz and Meyer-Lindenberg [150]. 
animal models were required to demonstrate that motivational and hedonic aspects of reinforcement were indeed neurobiologically dissociable $[48,67]$.

Pharmacological manipulations and other interventional techniques also provide tremendous advantages over imaging measures alone; these studies can identify plasticity dynamics that can help unpack some of the cross-sectional observations. For example, behavioral pharmacology studies of DA in MDD suggest that patients experience a much stronger euphoria response to amphetamine than controls $[154,155]$, possibly indicating an up-regulation of post-synaptic DA receptors sites and/or DAT. The cross-sectional imaging studies discussed above, however, suggest down-regulation of both D1 and D2 as well as DAT proteins. Since the expression of these proteins is dynamic, imaging studies done in conjunction with pharmacological challenges (withinsubject) hold the promise for stronger mechanistic inferences regarding how neurotransmitter systems are able to adapt to changing conditions in MDD. Such pharmacological challenges can therefore greatly aid in the understanding of plasticity within circuits, and help shift away from a focus on the identification of a stable, persistent pathological marker, which appears unlikely to exist.

Finally, circuit-based analysis may help facilitate a shift in the conceptualization and measurement of psychiatric symptom inventories that are often used to define groups and regress against imaging data. Psychiatric measurement largely relies on subjective self-reporting of distress as they sine qua non of symptom diagnosis. When it comes to reporting how one feels, however, studies in healthy populations have increasingly observed dissociation between the 'believing self' and the 'experiencing self' [156-158]. Accordingly, while the former describes how an individual summarizes their experience over a period of time, the latter refers to experiential reports made 'in the moment'. Whereas these constructs would theoretically be expected to correlate highly, growing evidence suggests that they are only moderately correlated at best $[157,159]$. This is in part due to the presence of wellknown retrospective biases that reflect a heightened sensitivity to recency or maximum intensity of emotional experiences (so-called 'peak and end' effects) [160]. In disorders like schizophrenia, such retrospective biases can result in almost completely uncorrelated findings of emotional response across retrospective and in-the-moment reports [161].

This renders significantly liable the common practice of regressing symptom severity measures (for example, the BDI-II) against imaging data [162], as both the independent and dependent measures likely reflect a complex mix of 'believing self' and 'experiencing self'. For example, if someone has reported severe depression over the past week, but happens to have a brief lifting during the two- to three-hour window in which the lab experiment occurs, it may be more important to consider the 'in the moment' affect rather than feelings aggregated over the past weeks when trying to interpret associated imaging data; this stands in contrast with the traditional assumption that individuals with shared symptom severity over a one-week period will have more variance in common than individuals with shared experience of a particular experimental task. One approach to addressing this challenge is the development of measures that seek to tease apart 'believing self' and 'experiencing self', with the aim of identifying separate biological correlates. It is likely that both are implicated in the maintenance of depressive symptoms [163], but current symptom assessment inventories are poorly suited to distinguish between these distinct modes of types of subjective report.

In sum, clinical imaging studies can contribute to circuit-based analysis through a focus on network-based analytical techniques, such as functional connectivity, multi-modal imaging methods, the use of within-subject pharmacological challenge designs, and greater sensitivity to potential discrepancies between 'believing self' and 'experiencing self' that may mask important distinctions in the relationships between subjective report and neuroimaging data.

\section{Conclusion}

The neuroimaging literature of depression has grown tremendously over the last several decades. The primary fruit of these efforts has been the identification of brain regions and structures that are most critical to the expression of depressive symptomatology, while also increasing our knowledge of how these regions interact with particular neurotransmitter systems, neurochemicals, hormones, and other signaling proteins. Despite a wealth of positive findings, translations to treatment remain elusive. Moving forward, the integration of these various methods through the use of circuit-based analysis will be critical for the development of a biologically-based nosology and personalized medicine in psychiatry.

\footnotetext{
Abbreviations

5-HT: Serotonin; ACC: anterior cingulate cortex; BOLD: blood-oxygen level-dependent; CNS: central nervous system; DA: dopamine; DAT: dopamine transporter; DBS: deep-brain stimulation; dIPFC: dorsolateral prefrontal cortex; Glu: glutamate; GABA: gamma-aminobutyric acid; HPA axis: hypothalamic-pituitary-adrenal axis; IFN: interferon; MDD: major depressive disorder; MID: monetary incentive delay; mPFC: medial prefrontal cortex; MRI: magnetic resonance imaging; MRS: magnetic resonance spectroscopy; NE: norepinephrine; NET: norepinephrine transporter; OFC: orbitofrontal cortex; PET: positron emission tomography; PFC: prefrontal cortex; ROI: region of interest; SPECT: single photon emission computed tomography; SERT: serotonin transporter; TMS: transcranial magnetic stimulation; TSH: thyroid stimulating hormone; VBM: voxel-based morphometry; vIPFC: ventrolateral prefrontal cortex.
} 


\section{Competing interests}

The authors declare no competing interests. Over the past three years, Dr. Pizzagalli received consulting/honoraria from AstraZeneca, Ono Pharma USA, Pfizer, Servier, and Shire for activities unrelated to the current review.

\section{Authors' contributions}

MTT and DAP developed the outline, MTT reviewed the relevant literature, and MTT and DAP wrote the manuscript. Both authors read and approved the final manuscript.

\section{Acknowledgements}

This work was funded by R01MH068376, R01MH06376S1, and R01MH095809 to DAP, and a McLean Corneel Fellowship to MTT. The authors also wish to thank two anonymous reviewers for their helpful comments.

Received: 19 November 2013 Accepted: 17 February 2014

Published: 7 March 2014

\section{References}

1. Kapur S, Phillips AG, Insel TR: Why has it taken so long for biological psychiatry to develop clinical tests and what to do about it? Mol Psychiatry 2012, 17:1174-1179.

2. Koolschijn PC, van Haren NE, Lensvelt-Mulders GJ, Hulshoff Pol HE, Kahn RS: Brain volume abnormalities in major depressive disorder: a meta-analysis of magnetic resonance imaging studies. Hum Brain Mapp 2009.

3. Kempton MJ, Salvador Z, Munafo MR, Geddes JR, Simmons A, Frangou S, Williams SC: Structural neuroimaging studies in major depressive disorder. Meta-analysis and comparison with bipolar disorder. Arch Gen Psychiatry 2011, 68:675-690.

4. Bora E, Fornito A, Pantelis C, Yucel M: Gray matter abnormalities in Major Depressive Disorder: a meta-analysis of voxel based morphometry studies. J Affect Disord 2011, 138:9-18.

5. Cotter D, Mackay D, Landau S, Kerwin R, Everall I: Reduced glial cell density and neuronal size in the anterior cingulate cortex in major depressive disorder. Arch Gen Psychiatry 2001, 58:545-553.

6. Liao Y, Huang X, Wu Q, Yang C, Kuang W, Du M, Lui S, Yue Q, Chan RC, Kemp GJ, Gong Q: Is depression a disconnection syndrome? Meta-analysis of diffusion tensor imaging studies in patients with MDD. J Psychiatry Neurosci 2013, 38:49-56.

7. Yucel K, McKinnon MC, Chahal R, Taylor VH, Macdonald K, Joffe R, MacQueen GM: Anterior cingulate volumes in never-treated patients with major depressive disorder. Neuropsychopharmacology 2008, 33:3157-3163.

8. McKinnon MC, Yucel K, Nazarov A, MacQueen GM: A meta-analysis examining clinical predictors of hippocampal volume in patients with major depressive disorder. J Psychiatry Neurosci 2009, 34:41-54

9. van Eijndhoven $P$, van Wingen $G$, van Oijen K, Rijpkema M, Goraj B, Jan Verkes R, Oude Voshaar R, Fernandez G, Buitelaar J, Tendolkar I: Amygdala volume marks the acute state in the early course of depression. Biol Psychiatry 2009, 65:812-818.

10. Frodl T, Meisenzahl EM, Zetzsche T, Hohne T, Banac S, Schorr C, Jager M, Leinsinger G, Bottlender R, Reiser M, Moller HJ: Hippocampal and amygdala changes in patients with major depressive disorder and healthy controls during a 1-year follow-up. J Clin Psychiatry 2004 65:492-499.

11. Frodl T, Jager M, Smajstrlova I, Born C, Bottlender R, Palladino T, Reiser M, Moller HJ, Meisenzahl EM: Effect of hippocampal and amygdala volumes on clinical outcomes in major depression: a 3-year prospective magnetic resonance imaging study. J Psychiatry Neurosci 2008, 33:423-430

12. Arnone D, McKie S, Elliott R, Juhasz G, Thomas EJ, Downey D, Williams S, Deakin JF, Anderson IM: State-dependent changes in hippocampal grey matter in depression. Mol Psychiatry 2012.

13. Schermuly I, Wolf D, Lieb K, Stoeter P, Fellgiebel A: State dependent posterior hippocampal volume increases in patients with majo depressive disorder. J Affect Disord 2011, 135:405-409.

14. Holmes AJ, Lee PH, Hollinshead MO, Bakst L, Roffman JL, Smoller JW, Buckner RL: Individual differences in amygdala-medial prefrontal anatomy link negative affect, impaired social functioning, and polygenic depression risk. J Neurosci 2012, 32:18087-18100.

15. Saleh K, Carballedo A, Lisiecka D, Fagan AJ, Connolly G, Boyle G, Frodl T: Impact of family history and depression on amygdala volume. Psychiatry Res 2012, 203:24-30.
16. Amico F, Meisenzahl E, Koutsouleris $\mathrm{N}$, Reiser M, Moller HJ, Frodl T: Structural MRI correlates for vulnerability and resilience to major depressive disorder. J Psychiatry Neurosci 2011, 36:15-22.

17. Hasler G, Northoff G: Discovering imaging endophenotypes for major depression. Mol Psychiatry 2011, 16:604-619.

18. Diener C, Kuehner C, Brusniak W, Ubl B, Wessa M, Flor H: A meta-analysis of neurofunctional imaging studies of emotion and cognition in major depression. Neuroimage 2012, 61:677-685.

19. Hamilton JP, Etkin A, Furman DJ, Lemus MG, Johnson RF, Gotlib $\Vdash$ : Functional neuroimaging of major depressive disorder: a meta-analysis and new integration of base line activation and neural response data. Am J Psychiatry 2012, 169:693-703.

20. Pizzagalli DA: Frontocingulate dysfunction in depression: toward biomarkers of treatment response. Neuropsychopharmacology 2011, 36:183-206.

21. Victor TA, Furey ML, Fromm SJ, Ohman A, Drevets WC: Relationship between amygdala responses to masked faces and mood state and treatment in major depressive disorder. Arch Gen Psychiatry 2010, 67:1128-1138.

22. Fu CH, Williams SC, Cleare AJ, Brammer MJ, Walsh ND, Kim J, Andrew CM, Pich EM, Williams PM, Reed L, Mitterschiffthaler MT, Suckling J, Bullmore ET: Attenuation of the neural response to sad faces in major depression by antidepressant treatment: a prospective, event-related functional magnetic resonance imaging study. Arch Gen Psychiatry 2004, 61:877-889.

23. Siegle GJ, Steinhauer SR, Thase ME, Stenger VA, Carter CS: Can't shake that feeling: event-related $\mathrm{FMRI}$ assessment of sustained amygdala activity in response to emotional information in depressed individuals. Biol Psychiatry 2002, 51:693-707.

24. Mitterschiffthaler MT, Williams SC, Walsh ND, Cleare AJ, Donaldson C, Scott J, Fu CH: Neural basis of the emotional Stroop interference effect in major depression. Psychol Med 2008, 38:247-256.

25. Siegle GJ, Thompson W, Carter CS, Steinhauer SR, Thase ME: Increased amygdala and decreased dorsolateral prefrontal BOLD responses in unipolar depression: related and independent features. Biol Psychiatry 2007, 61:198-209.

26. Beauregard $M$, Paquette $V$, Levesque J: Dysfunction in the neural circuitry of emotional self-regulation in major depressive disorder. Neuroreport $2006,17: 843-846$

27. Dillon DG, Pizzagalli DA: Evidence of successful modulation of brain activation and subjective experience during reappraisal of negative emotion in unmedicated depression. Psychiatry Res 2013, 212:99-107.

28. Erk S, Mikschl A, Stier S, Ciaramidaro A, Gapp V, Weber B, Walter H: Acute and sustained effects of cognitive emotion regulation in major depression. J Neurosci 2010, 30:15726-15734.

29. Johnstone T, van Reekum CM, Urry HL, Kalin NH, Davidson RJ: Failure to regulate: counterproductive recruitment of top-down prefrontal-subcortical circuitry in major depression. J Neurosci 2007, 27:8877-8884.

30. Matsuo K, Glahn DC, Peluso MA, Hatch JP, Monkul ES, Najt P, Sanches M, Zamarripa F, Li J, Lancaster JL, Fox PT, Gao JH, Soares JC: Prefrontal hyperactivation during working memory task in untreated individuals with major depressive disorder. Mol Psychiatry 2007, 12:158-166.

31. Wagner G, Sinsel E, Sobanski T, Kohler S, Marinou V, Mentzel HJ, Sauer H, Schlosser RG: Cortical inefficiency in patients with unipolar depression: an event-related FMRI study with the Stroop task. Biol Psychiatry 2006, 59:958-965.

32. Etkin A, Schatzberg AF: Common abnormalities and disorder-specific compensation during implicit regulation of emotional processing in generalized anxiety and major depressive disorders. Am J Psychiatry 2011, 168:968-978.

33. Beesdo K, Lau JY, Guyer AE, McClure-Tone EB, Monk CS, Nelson EE, Fromm SJ, Goldwin MA, Wittchen HU, Leibenluft E, Ernst M, Pine DS: Common and distinct amygdala-function perturbations in depressed versus anxious adolescents. Arch Gen Psychiatry 2009, 66:275-285.

34. Ochsner KN, Ray RD, Cooper JC, Robertson ER, Chopra S, Gabrieli JD, Gross $J$ J: For better or for worse: neural systems supporting the cognitive down- and up-regulation of negative emotion. Neuroimage 2004, 23:483-499.

35. Matthews SC, Strigo IA, Simmons AN, Yang TT, Paulus MP: Decreased functional coupling of the amygdala and supragenual cingulate is related to increased depression in unmedicated individuals with current major depressive disorder. J Affect Disord 2008, 111:13-20. 
36. Mitterschiffthaler MT, Kumari V, Malhi GS, Brown RG, Giampietro VP, Brammer MJ, Suckling J, Poon L, Simmons A, Andrew C, Sharma T: Neural response to pleasant stimuli in anhedonia: an $\mathrm{fMRI}$ study. Neuroreport 2003, 14:177-182.

37. Surguladze S, Brammer MJ, Keedwell P, Giampietro V, Young AW, Travis MJ, Williams SC, Phillips ML: A differential pattern of neural response toward sad versus happy facial expressions in major depressive disorder. Biol Psychiatry 2005, 57:201-209.

38. Keedwell PA, Andrew C, Williams SC, Brammer MJ, Phillips ML: A double dissociation of ventromedial prefrontal cortical responses to sad and happy stimuli in depressed and healthy individuals. Biol Psychiatry 2005, 58:495-503

39. Gotlib $\mid H$, Hamilton JP, Cooney RE, Singh MK, Henry ML, Joormann J: Neural processing of reward and loss in girls at risk for major depression. Arch Gen Psychiatry 2010, 67:380-387.

40. Dichter GS, Felder JN, Petty C, Bizzell J, Ernst M, Smoski MJ: The effects of psychotherapy on neural responses to rewards in major depression. Biol Psychiatry 2009, 66:886-897.

41. Forbes EE, Hariri AR, Martin SL, Silk JS, Moyles DL, Fisher PM, Brown SM, Ryan ND, Birmaher B, Axelson DA, Dahl RE: Altered striatal activation predicting real-world positive affect in adolescent major depressive disorder. Am J Psychiatry 2009, 166:64-73.

42. Pizzagalli DA, Holmes AJ, Dillon DG, Goetz EL, Birk JL, Bogdan R, Dougherty DD, losifescu DV, Rauch SL, Fava M: Reduced caudate and nucleus accumbens response to rewards in unmedicated individuals with major depressive disorder. Am J Psychiatry 2009, 166:702-710.

43. Kumar P, Waiter G, Ahearn T, Milders M, Reid I, Steele JD: Abnormal temporal difference reward-learning signals in major depression. Brain 2008, 131:2084-2093.

44. Pizzagalli DA, losifescu D, Hallett LA, Ratner KG, Fava M: Reduced hedonic capacity in major depressive disorder: evidence from a probabilistic reward task. J Psychiatr Res 2008, 43:76-87.

45. Clery-Melin ML, Schmidt L, Lafargue G, Baup N, Fossati P, Pessiglione M: Why don't you try harder? An investigation of effort production in major depression. PLoS One 2011, 6:e23178.

46. Sherdell L, Waugh $\mathrm{CE}$, Gotlib IH: Anticipatory pleasure predicts motivation for reward in major depression. J Abnorm Psychol 2011.

47. Treadway MT, Bossaller NA, Shelton RC, Zald DH: Effort-based decision-making in major depressive disorder: a translational model of motivational anhedonia. J Abnorm Psychol 2012.

48. Berridge KC: The debate over dopamine's role in reward: the case for incentive salience. Psychopharmacology (Berl) 2007, 191:391-431.

49. Treadway MT, Zald DH: Reconsidering anhedonia in depression: lessons from translational neuroscience. Neurosci Biobehav Rev 2011, 35:537-555.

50. Capuron L, Pagnoni G, Drake DF, Woolwine BJ, Spivey JR, Crowe RJ, Votaw $J R$, Goodman MM, Miller AH: Dopaminergic mechanisms of reduced basal ganglia responses to hedonic reward during interferon alfa administration. Arch Gen Psychiatry 2012, 69:1044-1053.

51. Hasler G, Fromm S, Carlson PJ, Luckenbaugh DA, Waldeck T, Geraci M Roiser JP, Neumeister A, Meyers N, Charney DS, Drevets WC: Neural response to catecholamine depletion in unmedicated subjects with major depressive disorder in remission and healthy subjects. Arch Gen Psychiatry 2008, 65:521-531.

52. Hasler G, Luckenbaugh DA, Snow J, Meyers N, Waldeck T, Geraci M, Roiser J, Knutson B, Charney DS, Drevets WC: Reward processing after catecholamine depletion in unmedicated, remitted subjects with major depressive disorder. Biol Psychiatry 2009, 66:201-205.

53. Heller AS, Johnstone T, Shackman AJ, Light SN, Peterson MJ, Kolden GG, Kalin NH, Davidson RJ: Reduced capacity to sustain positive emotion in major depression reflects diminished maintenance of fronto-striatal brain activation. Proc Natl Acad Sci U S A 2009, 106:22445-22450.

54. Schildkraut JJ: The catecholamine hypothesis of affective disorders: a review of supporting evidence. Am J Psychiatry 1965, 122:509-522.

55. Jacobs BL, Fornal CA: Activity of serotonergic neurons in behaving animals. Neuropsychopharmacology 1999, 21:9S-15S.

56. Daubert EA, Condron BG: Serotonin: a regulator of neuronal morphology and circuitry. Trends Neurosci 2010, 33:424-434.

57. Jasinska AJ, Lowry CA, Burmeister M: Serotonin transporter gene, stress and raphe-raphe interactions: a molecular mechanism of depression. Trends Neurosci 2012, 35:395-402.
58. Amat J, Baratta MV, Paul E, Bland ST, Watkins LR, Maier SF: Medial prefrontal cortex determines how stressor controllability affects behavior and dorsal raphe nucleus. Nat Neurosci 2005, 8:365-371.

59. Amat J, Paul E, Watkins LR, Maier SF: Activation of the ventral medial prefrontal cortex during an uncontrollable stressor reproduces both the immediate and long-term protective effects of behavioral control. Neuroscience 2008, 154:1178-1186.

60. Hammen C: Stress and depression. Annu Rev Clin Psychol 2005, 1:293-319.

61. Kessler RC: The effects of stressful life events on depression. Annu Rev Psychol 1997, 48:191-214.

62. Kendler KS, Karkowski LM, Prescott CA: Causal relationship between stressful life events and the onset of major depression. Am J Psychiatry 1999, 156:837-841.

63. Savitz JB, Drevets WC: Neuroreceptor imaging in depression. Neurobiol Dis 2013, 52:49-65.

64. Smith DF, Jakobsen S: Molecular neurobiology of depression: PET findings on the elusive correlation with symptom severity. Front Psychiatry 2013, 4:8.

65. Willner P: Dopamine and depression: a review of recent evidence. I. Empirical studies. Brain Res 1983, 287:211-224.

66. van Praag HM, Korf J, Schut D: Cerebral monoamines and depression. An investigation with the probenecid technique. Arch Gen Psychiatry 1973, 28:827-831

67. Salamone JD, Correa M: The mysterious motivational functions of mesolimbic dopamine. Neuron 2012, 76:470-485.

68. Schultz W: Behavioral dopamine signals. Trends Neurosci 2007, 30:203-210.

69. Barch DM, Dowd EC: Goal representations and motivational drive in schizophrenia: the role of prefrontal-striatal interactions. Schizophr Bull 2010, 36:919-934.

70. Treadway MT, Zald DH: Parsing anhedonia translational models of reward-processing deficits in psychopathology. Curr Dir Psychol Sci 2013, 22:244-249.

71. Agren H, Reibring L: PET studies of presynaptic monoamine metabolism in depressed patients and healthy volunteers. Pharmacopsychiatry 1994, 27:2-6.

72. Meyer JH, Kruger S, Wilson AA, Christensen BK, Goulding VS, Schaffer A, Minifie C, Houle S, Hussey D, Kennedy SH: Lower dopamine transporter binding potential in striatum during depression. Neuroreport 2001 12:4121-4125

73. Yang YK, Yeh TL, Yao WJ, Lee IH, Chen PS, Chiu NT, Lu RB: Greater availability of dopamine transporters in patients with major depression a dual-isotope SPECT study. Psychiatry Res 2008, 162:230-235.

74. Amsterdam JD, Newberg AB: A preliminary study of dopamine transporter binding in bipolar and unipolar depressed patients and healthy controls. Neuropsychobiology 2007, 55:167-170.

75. Laasonen-Balk T, Kuikka J, Viinamaki H, Husso-Saastamoinen M, Lehtonen J, Tiihonen J: Striatal dopamine transporter density in major depression. Psychopharmacology (Berl) 1999, 144:282-285.

76. Rahmim A, Zaidi H: PET versus SPECT: strengths, limitations and challenges. Nucl Med Commun 2008, 29:193-207.

77. Klimek V, Schenck JE, Han H, Stockmeier CA, Ordway GA: Dopaminergic abnormalities in amygdaloid nuclei in major depression: a postmortem study. Biol Psychiatry 2002, 52:740-748.

78. Shah PJ, Ogilvie AD, Goodwin GM, Ebmeier KP: Clinical and psychometric correlates of dopamine D2 binding in depression. Psychol Med 1997 27:1247-1256

79. D'Haenen HA, Bossuyt A: Dopamine D2 receptors in depression measured with single photon emission computed tomography. Biol Psychiatry 1994 , 35:128-132

80. Gershon AA, Vishne T, Grunhaus L: Dopamine D2-like receptors and the antidepressant response. Biol Psychiatry 2007, 61:145-153.

81. Parsey RV, Oquendo MA, Zea-Ponce Y, Rodenhiser J, Kegeles LS, Pratap M, Cooper TB, Van Heertum R, Mann JJ, Laruelle M: Dopamine D(2) receptor availability and amphetamine-induced dopamine release in unipolar depression. Biol Psychiatry 2001, 50:313-322.

82. Hirvonen J, Karlsson H, Kajander J, Markkula J, Rasi-Hakala H, Nagren K, Salminen JK, Hietala J: Striatal dopamine D2 receptors in medication-naive patients with major depressive disorder as assessed with [11C]raclopride PET. Psychopharmacology (Berl) 2008, 197:581-590.

83. Klimke A, Larisch R, Janz A, Vosberg H, Muller-Gartner HW, Gaebel W: Dopamine $\mathrm{D} 2$ receptor binding before and after treatment of major depression measured by [123I]IBZM SPECT. Psychiatry Res 1999, 90:91-101. 
84. Cannon DM, Klaver JM, Peck SA, Rallis-Voak D, Erickson K, Drevets WC Dopamine type-1 receptor binding in major depressive disorder assessed using positron emission tomography and [11C]NNC-112. Neuropsychopharmacology 2009, 34:1277-1287.

85. Sarchiapone M, Carli V, Camardese G, Cuomo C, Di Giuda D, Calcagni ML, Focacci C, De Risio S: Dopamine transporter binding in depressed patients with anhedonia. Psychiatry Res 2006, 147:243-248.

86. Martinot M, Bragulat V, Artiges E, Dolle F, Hinnen F, Jouvent R, Martinot J: Decreased presynaptic dopamine function in the left caudate of depressed patients with affective flattening and psychomotor retardation. Am J Psychiatry 2001, 158:314-316.

87. Bragulat $\mathrm{V}$, Paillere-Martinot ML, Artiges $\mathrm{E}$, Frouin $\mathrm{V}$, Poline JB, Martinot $J$ : Dopaminergic function in depressed patients with affective flattening or with impulsivity: [18 F]fluoro-L-dopa positron emission tomography study with voxel-based analysis. Psychiatry Res 2007, 154:115-124.

88. Haroon E, Raison CL, Miller AH: Psychoneuroimmunology meets neuropsychopharmacology: translational implications of the impact of inflammation on behavior. Neuropsychopharmacology 2011 37:137-162.

89. Takano H, Arakawa R, Nogami T, Suzuki M, Nagashima T, Fujiwara H, Kimura Y, Kodaka F, Takahata K, Shimada H: Norepinephrine transporter occupancy by nortriptyline in patients with depression: a positron emission tomography study with (S, S)-[18F] FMeNER-D2. Int J Neuropsychopharmaco 2013:1-8.

90. van Wingen GA, Tendolkar I, Urner M, van Marle H, Denys D, Verkes R-J, Fernandez G: Short-term antidepressant administration reduces default mode and task-positive network connectivity in healthy individuals during rest. Neuroimage 2013.

91. Ossewaarde L, Verkes RJ, Hermans EJ, Kooijman SC, Urner M, Tendolkar I, van Wingen GA, Fernandez G: Two-week administration of the combined serotonin-noradrenaline reuptake inhibitor duloxetine augments functioning of mesolimbic incentive processing circuits. Biol Psychiatry 2011, 70:568-574.

92. Bruhl $A B$, Jancke $L$, Herwig U: Differential modulation of emotion processing brain regions by noradrenergic and serotonergic antidepressants. Psychopharmacology (Berl) 2011, 216:389-399.

93. Bruhl $A B$, Kaffenberger T, Herwig U: Serotonergic and noradrenergic modulation of emotion processing by single dose antidepressants. Neuropsychopharmacology 2010, 35:521

94. Ressler KJ, Nemeroff CB: Role of norepinephrine in the pathophysiology and treatment of mood disorders. Biol Psychiatry 1999, 46:1219-1233.

95. Sanacora G, Treccani G, Popoli M: Towards a glutamate hypothesis of depression: an emerging frontier of neuropsychopharmacology for mood disorders. Neuropharmacology 2012, 62:63-77.

96. Altamura CA, Mauri MC, Ferrara A, Moro AR, D'Andrea G, Zamberlan F: Plasma and platelet excitatory amino acids in psychiatric disorders. Am J Psychiatry 1993, 150:1731-1733.

97. Kim JS, Schmid-Burgk W, Claus D, Kornhuber HH: Increased serum glutamate in depressed patients. Arch Psychiatr Nervenkr 1982, 232:299-304.

98. Hashimoto K, Sawa A, lyo M: Increased levels of glutamate in brains from patients with mood disorders. Biol Psychiatry 2007, 62:1310-1316.

99. Yuksel C, Ongur D: Magnetic resonance spectroscopy studies of glutamate-related abnormalities in mood disorders. Biol Psychiatry 2010, 68:785-794.

100. Luykx JJ, Laban KG, van den Heuvel MP, Boks MP, Mandl RC, Kahn RS, Bakker SC: Region and state specific glutamate downregulation in major depressive disorder: a meta-analysis of (1)H-MRS findings. Neurosci Biobehav Rev 2011, 36:198-205.

101. Jarnum H, Eskildsen SF, Steffensen EG, Lundbye-Christensen S, Simonsen CW Thomsen IS, Frund ET, Theberge J, Larsson EM: Longitudinal MRI study of cortical thickness, perfusion, and metabolite levels in major depressive disorder. Acta Psychiatr Scand 2011, 124:435-446.

102. Portella MJ, de Diego-Adelino J, Gomez-Anson B, Morgan-Ferrando R, Vives Y Puigdemont D, Perez-Egea R, Ruscalleda J, Enric A, Perez V: Ventromedial prefrontal spectroscopic abnormalities over the course of depression: a comparison among first episode, remitted recurrent and chronic patients. J Psychiatr Res 2010, 45:427-434.

103. Merkl A, Schubert F, Quante A, Luborzewski A, Brakemeier EL, Grimm S, Heuser I, Bajbouj M: Abnormal cingulate and prefrontal cortical neurochemistry in major depression after electroconvulsive therapy. Biol Psychiatry 2010, 69:772-779.
104. Kondo DG, Hellem TL, Sung YH, Kim N, Jeong EK, Delmastro KK, Shi X, Renshaw PF: Review: magnetic resonance spectroscopy studies of pediatric major depressive disorder. Depress Res Treat 2011, 2011:650450.

105. Deschwanden A, Karolewicz B, Feyissa AM, Treyer V, Ametamey SM, Johayem A, Burger C, Auberson YP, Sovago J, Stockmeier CA, Buck A, Hasler $\mathrm{G}$ : Reduced metabotropic glutamate receptor 5 density in major depression determined by [11C]ABP688 PET and postmortem study. Am J Psychiatry 2011, 168:727-734.

106. Hefti K, Holst SC, Sovago J, Bachmann V, Buck A, Ametamey SM, Scheidegger M, Berthold T, Gomez-Mancilla B, Seifritz E: Increased metabotropic glutamate receptor subtype 5 availability in human brain after one night without sleep. Biol Psychiatry 2013.

107. Berman RM, Cappiello A, Anand A, Oren DA, Heninger GR, Charney DS, Krystal JH: Antidepressant effects of ketamine in depressed patients. Biol Psychiatry 2000, 47:351-354

108. Zarate CA Jr, Singh JB, Carlson PJ, Brutsche NE, Ameli R, Luckenbaugh DA, Charney DS, Manji HK: A randomized trial of an N-methyl-D-aspartate antagonist in treatment-resistant major depression. Arch Gen Psychiatry 2006, 63:856-864.

109. Luscher B, Shen Q, Sahir N: The GABAergic deficit hypothesis of major depressive disorder. Mol Psychiatry 2010, 16:383-406.

110. Petty F, Schlesser MA: Plasma GABA in affective illness. A preliminary investigation. J Affect Disord 1981, 3:339-343.

111. Petty F, Sherman AD: GABAergic modulation of learned helplessness. Pharmacol Biochem Behav 1981, 15:567-570.

112. Gerner RH, Hare TA: CSF GABA in normal subjects and patients with depression, schizophrenia, mania, and anorexia nervosa. Am J Psychiatry 1981, 138:1098-1101.

113. Hasler G, van der Veen JW, Tumonis T, Meyers N, Shen J, Drevets WC: Reduced prefrontal glutamate/glutamine and gamma-aminobutyric acid levels in major depression determined using proton magnetic resonance spectroscopy. Arch Gen Psychiatry 2007, 64:193-200.

114. Gabbay V, Mao X, Klein RG, Ely BA, Babb JS, Panzer AM, Alonso CM, Shungu DC: Anterior cingulate cortex gamma-aminobutyric acid in depressed adolescents: relationship to anhedonia. Arch Gen Psychiatry 2012 69:139-149.

115. Radley JJ, Sawchenko PE: A common substrate for prefrontal and hippocampal inhibition of the neuroendocrine stress response. J Neurosci 2011, 31:9683-9695

116. Radley JJ, Gosselink KL, Sawchenko PE: A discrete GABAergic relay mediates medial prefrontal cortical inhibition of the neuroendocrine stress response. J Neurosci 2009, 29:7330-7340.

117. Homan P, Drevets WC, Hasler G: Neural correlates of free T3 alteration after catecholamine depletion in subjects with remitted major depressive disorder and in controls. Psychopharmacology (Berl) 2014, 231:409-417.

118. Homan P, Grob S, Milos G, Schnyder U, Hasler G: Reduction in total plasma ghrelin levels following catecholamine depletion: relation to bulimic and depressive symptoms. Psychoneuroendocrinology 2013.

119. McEwen BS: Physiology and neurobiology of stress and adaptation: central role of the brain. Physiol Rev 2007, 87:873-904.

120. Sapolsky RM: Glucocorticoids and hippocampal atrophy in neuropsychiatric disorders. Arch Gen Psychiatry 2000, 57:925-935.

121. Radley JJ, Rocher AB, Miller M, Janssen WG, Liston C, Hof PR, McEwen BS, Morrison $\mathrm{JH}$ : Repeated stress induces dendritic spine loss in the rat medial prefrontal cortex. Cereb Cortex 2006, 16:313-320.

122. Cook SC, Wellman CL: Chronic stress alters dendritic morphology in rat medial prefrontal cortex. J Neurobiol 2004, 60:236-248.

123. Cerqueira JJ, Pego JM, Taipa R, Bessa JM, Almeida OF, Sousa N: Morphological correlates of corticosteroid-induced changes in prefrontal cortex-dependent behaviors. J Neurosci 2005, 25:7792-7800.

124. McEwen BS: Stress and hippocampal plasticity. Annu Rev Neurosci 1999, 22:105-122.

125. Treadway MT, Grant MM, Ding Z, Hollon SD, Gore JC, Shelton RC: Early adverse events, HPA activity and rostral anterior cingulate volume in MDD. PLoS One 2009, 4:e4887.

126. Dowlati Y, Herrmann N, Swardfager W, Liu H, Sham L, Reim EK, Lanctot KL: A meta-analysis of cytokines in major depression. Biol Psychiatry 2010, 67:446-457.

127. Zorrilla EP, Luborsky L, McKay JR, Rosenthal R, Houldin A, Tax A, McCorkle R, Seligman DA, Schmidt K: The relationship of depression and stressors to 
immunological assays: a meta-analytic review. Brain Behav Immun 2001, 15:199-226.

128. Shelton RC, Miller AH: Eating ourselves to death (and despair): the contribution of adiposity and inflammation to depression. Prog Neurobio/ 2010, 91:275-299.

129. Papakostas Gl, Shelton RC, Kinrys G, Henry ME, Bakow BR, Lipkin SH, Pi B, Thurmond L, Bilello JA: Assessment of a multi-assay, serum-based biological diagnostic test for major depressive disorder: a Pilot and Replication Study. Mol Psychiatry 2011.

130. Miller $\mathrm{AH}$, Maletic $\mathrm{V}$, Raison $\mathrm{CL}$ : Inflammation and its discontents: the role of cytokines in the pathophysiology of major depression. Biol Psychiatry 2009, 65:732-741.

131. Dantzer R, O'Connor JC, Freund GG, Johnson RW, Kelley KW: From inflammation to sickness and depression: when the immune system subjugates the brain. Nat Rev Neurosci 2008, 9:46-56.

132. Dantzer R, Meagher MW, Cleeland CS: Translational approaches to treatment-induced symptoms in cancer patients. Nat Rev Clin Oncol 2012, 9:414-426.

133. Felger JC, Mun J, Kimmel HL, Nye JA, Drake DF, Hernandez CR, Freeman AA, Rye DB, Goodman MM, Howell LL: Chronic interferon-a decreases dopamine 2 receptor binding and striatal dopamine release in association with anhedonia-like behavior in nonhuman primates. Neuropsychopharmacology 2013

134. Felger JC, Alagbe O, Hu F, Mook D, Freeman AA, Sanchez MM, Kalin NH, Ratti $E$, Nemeroff CB, Miller AH: Effects of interferon-alpha on rhesus monkeys: a nonhuman primate model of cytokine-induced depression. Biol Psychiatry 2007, 62:1324-1333.

135. Nunes EJ, Randall PA, Estrada A, Epling B, Hart EE, Lee CA, Baqi Y, Mueller CE, Correa M, Salamone JD: Effort-related motivational effects of the pro-inflammatory cytokine interleukin 1-beta: studies with the concurrent fixed ratio 5/chow feeding choice task. Psychopharmacology (Berl) 2014, 231:727-736.

136. Hannestad J, DellaGioia N, Gallezot J-D, Lim K, Nabulsi N, Esterlis I, Pittman B, Lee J-YO, Pelletier D, ÄôConnor KC: The neuroinflammation marker translocator protein is not elevated in individuals with mild-to-moderate depression: A [< sup > 11</sup > C] PBR28 PET study. Brain Behav Immun 2013, 33:131-138.

137. Eisenberger NI, Berkman ET, Inagaki TK, Rameson LT, Mashal NM, Irwin MR Inflammation-induced anhedonia: endotoxin reduces ventral striatum responses to reward. Biol Psychiatry 2010, 68:748-754.

138. McGrath CL, Kelley ME, Holtzheimer PE, Dunlop BW, Craighead WE, Franco AR, Craddock RC, Mayberg HS: Toward a neuroimaging treatment selection biomarker for major depressive disorder. JAMA Psychiatry 2013, 70:821-829.

139. Malone DA Jr, Dougherty DD, Rezai AR, Carpenter LL, Friehs GM, Eskandar EN, Rauch SL, Rasmussen SA, Machado AG, Kubu CS, Tyrka AR, Price LH, Stypulkowski PH, Giftakis JE, Rise MT, Malloy PF, Salloway SP, Greenberg BD: Deep brain stimulation of the ventral capsule/ventral striatum for treatment-resistant depression. Biol Psychiatry 2009, 65:267-275.

140. Mayberg HS, Lozano AM, Voon V, McNeely HE, Seminowicz D, Hamani C, Schwalb JM, Kennedy SH: Deep brain stimulation for treatment-resistant depression. Neuron 2005, 45:651-660.

141. Carpenter LL, Janicak PG, Aaronson ST, Boyadjis T, Brock DG, Cook IA, Dunner DL, Lanocha K, Solvason HB, Demitrack MA: Transcranial magnetic stimulation (TMS) for major depression: a multisite, naturalistic, observational study of acute treatment outcomes in clinical practice. Depress Anxiety 2012, 29:587-596.

142. Raison $\mathrm{CL}$, Miller $\mathrm{AH}$ : Is depression an inflammatory disorder? Curr Psychiatry Rep 2011, 13:467-475.

143. Cooper JC, Bloom FE, Roth RH: The Biochemical Basis of Neuropharmacology. 8th edition. New York: Oxford University Press; 2003.

144. Insel T, Cuthbert B, Garvey M, Heinssen R, Pine DS, Quinn K, Sanislow C, Wang P: Research domain criteria $(\mathrm{RDoC})$ : toward a new classification framework for research on mental disorders. Am J Psychiatry 2010, 167:748-751.

145. Akil H, Brenner S, Kandel E, Kendler KS, King MC, Scolnick E, Watson JD, Zoghbi HY: Medicine. The future of psychiatric research: genomes and neural circuits. Science 2010, 327:1580-1581.

146. Nestler EJ, Hyman SE: Animal models of neuropsychiatric disorders. Nat Neurosci 2010, 13:1161-1169.
147. Deisseroth K: Circuit dynamics of adaptive and maladaptive behaviour. Nature 2014, 505:309-317.

148. Bullmore ET, Bassett DS: Brain graphs: graphical models of the human brain connectome. Annu Rev Clin Psychol 2011, 7:113-14

149. Bullmore E, Sporns O: Complex brain networks: graph theoretical analysis of structural and functional systems. Nat Rev Neurosci 2009, 10:186-198.

150. Buckholtz JW, Meyer-Lindenberg A: Psychopathology and the human connectome: toward a transdiagnostic model of risk for mental illness. Neuron 2012, 74:990-1004.

151. Friston KJ, Ashburner JT, Kiebel SJ, Nichols TE, Penny WD: Statistical Parametric Mapping: the Analysis of Functional Brain Images. Academic; 2011.

152. Walter M, Henning A, Grimm S, Schulte RF, Beck J, Dydak U, Schnepf B, Boeker $H$, Boesiger $P$, Northoff $G$ : The relationship between aberrant neuronal activation in the pregenual anterior cingulate, altered glutamatergic metabolism, and anhedonia in major depression. Arch Gen Psychiatry 2009, 66:478-486.

153. Kring AM, Sloan DM: Emotion Regulation and Psychopathology: a Transdiagnostic Approach to Etiology and Treatment. New York, NY: The Guilford Press; 2010.

154. Tremblay LK, Naranjo CA, Cardenas L, Herrmann N, Busto UE: Probing brain reward system function in major depressive disorder: altered response to dextroamphetamine. Arch Gen Psychiatry 2002, 59:409-416.

155. Tremblay LK, Naranjo CA, Graham SJ, Herrmann N, Mayberg HS, Hevenor S, Busto UE: Functional neuroanatomical substrates of altered reward processing in major depressive disorder revealed by a dopaminergic probe. Arch Gen Psychiatry 2005, 62:1228-1236.

156. Kahneman D, Riis J: Living, and thinking about it: two perspectives on life. In The science of well-being. Edited by Huppert FA, Baylis N, Keverne B. New York, NY: Oxford University Press; 2005.

157. Conner TS, Barrett LF: Trends in ambulatory self-report: the role of momentary experience in psychosomatic medicine. Psychosom Med 2012, 74:327-337.

158. Kahneman D, Krueger AB, Schkade D, Schwarz N, Stone AA: Would you be happier if you were richer? A focusing illusion. Science 2006, 312:1908-1910.

159. Kahneman $D$, Deaton A: High income improves evaluation of life but not emotional well-being. Proc Natl Acad Sci 2010, 107:16489-16493.

160. Schwarz N: Retrospective and concurrent self-reports: the rationale for real-time data capture. In The Science of Real-Time Data Caputre: Self-Reports in Health Research. Google e-book; 2007:11-26.

161. Strauss GP, Gold JM: A new perspective on anhedonia in schizophrenia. Am J Psychiatry 2012.

162. Kagan J: A trio of concerns. Perspect Psychol Sci 2007, 2:361-376.

163. Beck AT, Haigh E: The generic cognitive model. Annu Rev Clin Psychol 2013, 10.

doi:10.1186/2045-5380-4-5

Cite this article as: Treadway and Pizzagalli: Imaging the pathophysiology of major depressive disorder - from localist models to circuit-based analysis. Biology of Mood \& Anxiety Disorders 2014 4:5.

\section{Submit your next manuscript to BioMed Central and take full advantage of:}

- Convenient online submission

- Thorough peer review

- No space constraints or color figure charges

- Immediate publication on acceptance

- Inclusion in PubMed, CAS, Scopus and Google Scholar

- Research which is freely available for redistribution 